\title{
Política Nacional de Assistência Social e território: enigmas do caminho
}

Tatiana Dahmer Pereira

Universidade Federal Fluminense (UFF)

\section{Política Nacional de Assistência Social e território: enigmas do caminho}

Resumo: Este ensaio problematiza, a partir da perspectiva de David Harvey, se e quanto o enfoque e a centralidade sobre a categoria território, no âmbito da atual política nacional de assistência social, configuram-na como inovação institucional. E se são capazes de concretizar, na implementação de políticas, diretrizes que confirmem à assistência social o status de política pública, conforme enunciado na Constituição Federal de 1988 e na Lei Orgânica de Assistência Social. Para tanto, recupera, brevemente, a presença histórica da dimensão espacial nas ações de assistência social de enfrentamento da questão social, indicando o início tardio da tematização sobre território. Por fim, problematiza elementos-chave, necessários à territorialização cidadã de políticas públicas, relacionados à participação e ao controle social.

Palavras-chave: Política Nacional de Assistência Social, território, cidadania.

\section{National Social Assistance Policy and Territory: Enigmas of the Path}

Abstract: Based on concepts developed by David Harvey, this essay analyzes if and to what extent a focus and concentration on the category of territory in the realm of current national social assistance policy is an institutional innovation. It questions if it is capable of establishing guidelines for the implementation of policies that confirm social assistance's status as a public policy, as established by the Federal Constitution of 1988 and the Organic Social Assistance Law. The paper briefly reviews the historic presence of the spatial dimension in social assistance actions that confront the social question, indicating the initiation of the recognition of the importance of territory. In conclusion, it analyzes key elements needed for the "citizen-territorialization" of public policies, related to participation and social control.

Key words: National Social Assistance Policy, territory, citizenship. 


\section{Apresentação}

Esse artigo reflete sobre a concepção de territorialização em curso na Política Nacional de Assistência Social (PNAS), através do Sistema Único de Assistência Social (SUAS). Partimos do princípio que hoje o maior desafio dessa política pública é assegurar que seu projeto político-institucional viabilize condições necessárias para superação, por parte da assistência social, de seu caráter de política para amenização e/ou erradicação da pobreza, para afirmar-se como política de cidadania ${ }^{2}$, contribuindo para o enfrentamento das desigualdades sociais.

Identificamos que o modelo atual - a partir da proposição da territorialização de serviços e equipamentos, sob o ordenamento do SUAS -, não consegue romper com o que consideramos uma convivência predatória da dualidade de modelos de políticas públicas. Essa convivência é hegemonizada pela primazia da racionalidade histórica que orienta diferentes modelos de reprodução das condições da acumulação capitalista com base no ordenamento territorial.

Partindo da percepção que "territorializar não significa, automaticamente, universalizar o acesso ao direito, nem tampoucoé sinônimo de descentralização", demonstraremos como a dimensão territorial nas ações estatais da assistência social brasileira não é uma novidade institucional. Ainda que recente, a tematização do território no âmbito da disciplina de Serviço Social pode ser identificada, historicamente, desde primórdios do século 20 no Brasil. No entanto, é nova, e ainda inconclusa, a perspectiva de territorialização visando à universalização e à consagração de direitos de cidadania, propostos por de princípios e diretrizes da Lei Orgânica de Assistência Social (LOAS, 1993) e da PNAS.

Considerando esses desafios e a dualidade anteriormente exposta, temos por referência analítica a proposição de David Harvey, segundo a qual a dimensão espacial e sua ressignificação como território conformam dimensão estratégica para a criação de condições da acumulação capitalista ${ }^{3}$. Partimos de breve histórico sobre a relação entre ordenamento territorial e formas estatais de enfrentamento das manifestações da questão social ${ }^{4}$ no Brasil, com particular enfoque sobre a assistência social. Por fim, dialogamos com a concepção vigente, problematizando a dimensão do fortalecimento da participação e das esferas públicas de controle social como um dos caminhos para superação de obstáculos de universalização dessa política pública como direito de cidadania.

\section{Assistência social e dimensão territorial: alguns elementos para reflexão}

Com a aprovação da PNAS (PNAS, 2004), inicia-se o processo de configuração do Sistema
Único de Assistência Social (SUAS) ${ }^{5}$ inspirado no modelo do Sistema Único de Saúde (SUS) 6 . Um dos pontos centrais relacionados à construção do sistema é a utilização da categoria de território como fundante das possibilidades expressas pelos princípios da Lei Orgânica de Assistência Social (LOAS, 1993, artigo 4) "de acessibilidade, da garantia de universalidade, da supremacia do atendimento às necessidades sobre exigências de rentabilidade econômica e de democratização" de informações sobre equipamentos, programas e critérios de concessão com vistas à proteção social de cidadania.

Com base em Harvey (2005), partimos da compreensão de que a dinâmica de (re)produção e de acumulação capitalista não tem como prescindir tanto da dimensão temporal, quanto da "dimensão espacial". Necessariamente incide sobre sua produção e reprodução, objetivando garantir as condições da acumulação e a constante busca da coerência regional estruturada ${ }^{7}$-, tornando espaços territórios $^{8}$. Para tanto, a desaceleração produzida no tempo de rotação necessário à realização da mercadoria como tal ${ }^{9}$ é força motriz da reprodução do capital como relação social, principalmente ao assegurar este como mecanismo de enfrentamento de suas crises endógenas.

A desaceleração promovida com vistas ao enfrentamento de crises de superacumulação pode ser compreendida como a dinâmica de constituição e uso do fundo público ${ }^{10}$, o qual desempenha papel primordial, ao contribuir, em outro tempo, com o processo de reprodução do capital, através do caráter ambíguo das políticas públicas, em especial, as políticas sociais (COUTO, 2004).

A articulação de dinâmicas espaço-temporais permite a estruturação espacial de forma a refletir necessidades de reprodução das condições de acumulação. Nessa linha, podemos afirmar que são expressas no espaço, a partir de investimentos estatais em políticas públicas, marcas contraditórias das disputas entre as classes "sociais". Nossa compreensão partilha da percepção que tais expressões da luta de classes incidem sobre formas dinâmicas de ordenamento espacial, ressignificando espaços em "territórios".

Sob essa abordagem, a dimensão territorial já se encontrava presente, ao menos pela perspectiva de espacialização dos investimentos, desde os primórdios da implementação das ações de assistência social pelo Estado brasileiro. Sem incorrer no equívoco de equalizar a "dimensão espacial" à categoria de "território", afirmamos que essa política pública sempre apresentou impacto territorial, ainda que suas ações fossem "projetadas espacialmente", sem maiores tematizações sobre a constituição dos territórios. 


\section{Expressão territorial: inovação institucional na assistência social?}

É na Primeira República (1889-1930) que ocorre a federalização dos estados, inspirada no modelo norteamericano, porém subordinando-se ao forte comando das oligarquias locais, em manifestação conhecida como coronelismo ${ }^{11}$. Esse advento é um dos elementos que não permitem a introdução de grandes transformações republicanas no que tange aos direitos de uma forma geral, tampouco assegura melhorias substantivas - principalmente aos ex-escravos e exescravas mesmo com a promulgação da Lei Áurea $(1888)^{12}$. Após o decreto formal do término da escravidão, no início do século 20 quando da conformação dos centros urbanos, no caso específico da Região Sudeste, ocorrem de forma mais permanente conflitos impulsionados pela explosão da questão social daquele momento histórico.

Paradoxalmente, na primeira década do século 20, a cidade do Rio de Janeiro é palco de radicais intervenções estatais de modificação da geografia urbana com a abertura das grandes vias impulsionadas pelo desejo de modernizar o país, inspiradas pelo higienismo e nos modelos das grandes metrópoles europeias. Sob o discurso da modernização, havia o pretexto de enfrentamento das epidemias e doenças emergentes a partir do agravamento da acelerada conformação urbana ${ }^{13}$.

Lembramos que no início do século 20, quando tem início o tardio e acelerado processo de urbanização e a transição do modelo agrário-exportador para a industrialização, visando integrar o Brasil à dinâmica capitalista mundial, emergem práticas de assistência ainda restritas a iniciativas privadas como forma de enfrentar manifestações da questão social do incipiente processo de formação das cidades. A assunção, por parte do Estado brasileiro, em larga escala de medidas assistenciais, combinadas com medidas coercitivas, a partir de de Vargas (1930), explicitam o processo de integração entre assistência social e intervenção territorial com objetivos de criar condições de civilidade necessárias à modernização do país ${ }^{14}$. Portanto, a emergência do urbano e da noção de modernidade em nosso país tem por base o modelo agrário-exportador em base escravocrata, configurando elementos particulares determinantes da questão social brasileira.

Destarte, a emergência de intervenções estatais através de políticas sociais, no início do século 20 possui como foco central o enfrentamento e apaziguamento dos conflitos das classes em constituição - e não a noção de princípios de urbanidade e mesmo criação de uma "institucionalidade liberal" (SANTOS, 1993), de garantia de direitos ou de formação de cidadãos. Essa racionalidade está estruturalmente vinculada à conformação da assistência social in- tegrada à racionalidade de organização/modernização do território, especialmente no Brasil - e sem se constituir em sua única determinante ${ }^{15}$.

Tais demandas de expansão do capital no processo embrionário desse novo modo de produção no Brasil impulsionaram que ex-escravos/as compusessem parcialmente a mão de obra assalariada e que a cidade apresentasse as "primeiras formas institucionais capitalistas no Brasil" (OLIVEIRA, 2003) ${ }^{16}$. Além disso, a produção de excedentes e a necessidade de seu escoamento a partir de uma incipiente dinâmica capitalista impulsionaram a acelerada industrialização, acompanhada de um modelo de urbanização inspirado nos padrões e concepções europeus - conformando condições particulares à estruturação do capitalismo, das classes sociais (OLIVEIRA, 2003) e de seus conflitos e, necessariamente, dos direitos no Brasil.

Mas, longe das intervenções apresentarem uma dimensão de planejamento para as contradições emergentes, a inspiração nas metrópoles internacionais orientava ações voltadas para a modernização e o embelezamento. Esse olhar para fora construiu modelos de segregação das classes populares que viviam em "territórios de exclusão e de informalidade e da não vigência de normas" (RIBEIRO; CARDOSO, 1996, p. 60).

A aceleração do processo de industrialização gerava, portanto, a urgência necessária de adequação da mão de obra a uma nova lógica de regulação social. Assim, as intervenções estatais, nesse tempo, não se voltavam para a garantia de direitos, mas para a construção das condições necessárias à implementação do capitalismo no Brasil (BEHRING; BOSCHETTI, 2007). Sem tematização, o espaço ia sendo adequado para propiciar essa modernização.

As intervenções assistenciais iniciam-se calcadas no apoio da filantropia religiosa e vivenciavam, em relação a essa referência, uma ruptura com a pressão exercida pelo acirramento dos conflitos urbanos e a agudização da questão social, onde esse método "doméstico" não conseguia enfrentar as demandas do urbano no Brasil. A crescente profissionalização das práticas de assistência com a assunção formal pelo Estado, na perspectiva liberal, de práticas de assistência social, impingiam métodos, como vimos, de intervenção territorial no âmbito das comunidades pobres, com vistas ao seu ordenamento funcional.

Seguindo a análise de Harvey (1989), que demonstra como a lógica vigente de organização do espaço urbano nos países europeus não conseguia aprisionar nem conter as dinâmicas contraditórias de classe, percebemos que, no (re)desenho das cidades brasileiras em formação, elementos históricos e particulares à formação econômica brasileira, como a escravidão e a estrutura agrária, conviviam contraditoriamente com os paradigmas da modernidade trazidos da Europa. 
Ao longo dos anos, a assistência social se profissionaliza e um dos sujeitos profissionais que a exercem - os/as assistentes sociais - passam a ter na disciplina do Serviço Social um campo de sistematização de conhecimento. Na medida em que a questão social se complexifica e passa a exigir maior tecnificação da profissão ${ }^{17}$, a resposta decorre da assimilação de vertentes teóricas, com algumas das ações no campo metodológico, apresentando claramente a valorização do espaço ${ }^{18}$.

O processo de urbanização, as contradições e a segregação social - ingredientes da chamada questão social - impulsionam a crescente intervenção do Estado, cujo conjunto de ações é marcado por todo período desenvolvimentista e nos anos de ditadura militar pós-1964, pela lógica de modernização conservadora.

Iamamoto e Carvalho (1991, p. 346) demonstram como a década das maiores transformações para a profissão são, justamente, os anos de 1960, quando se acirra a perspectiva desenvolvimentista e a "modernização" da intervenção profissional torna-se vital: “[...] assumem novo relevo e aplicação mais intensiva os métodos de serviço social de grupo e, especialmente, de comunidade". Essa instrumentalidade, refletindo o então projeto profissional hegemônico, relaciona-se com processos contraditórios de readequação dos espaços. Expressos através dos conflitos na reprodução da vida material, impelem, também, a formatação da dinâmica social e produzem, consequentemente, interações permanentes, influenciando na significação dos espaços e produção de territórios.

No período da redemocratização, em especial com o processo da Constituinte, floresce o debate em torno da afirmação de direitos humanos e de sua universalização. É nesse momento que são lançadas as bases do atual debate em torno da territorialização da assistência social.

Não obstante, em contraposição à proposta constitucional de universalização de direitos, as políticas sociais de corte neoliberal, financiadas por organizações multilaterais, em especial após as das medidas de ajuste fiscal ${ }^{19}$ impostas aos - denominados - "países em desenvolvimento", já operavam com princípios de territorialização dos investimentos. A partir de investimentos mínimos e focalizados do Estado, visavam assegurar o enfrentamento da pobreza com foco nas populações "pobres".

Combinam, assim, intervenções urbanas com políticas sociais sob a lógica de "combate à pobreza" e voltam-se à reprodução da vida junto aos grupos escolhidos. Essa abordagem não apresenta consonância com a proposta constitucional de criação de grandes sistemas nacionais de políticas públicas, financiadas a partir de fundos próprios e voltadas à universalização do direito ${ }^{20}$, mas encontra lugar de destaque na racionalidade da contrarreforma do Estado brasileiro nos anos de 1990.
Nesse sentido, reconhecemos em três períodos históricos a presença factual e/ou conceitual da dimensão territorial como uma das dimensões orientadoras das políticas públicas no campo da assistência social.

Um primeiro, entre 1930 e 1945, no qual o território não é tematizado, porém ocorrem intervenções estatais, articulando coerção e consenso, de forma cada vez mais ampliada para adequação das "massas perigosas" e enfrentamento dos incipientes conflitos de classes visando a integração à racionalidade do trabalho assalariado com claro impacto espacial. Junto à materialização de direitos trabalhistas e previdenciários, são criadas as grandes estruturas assistenciais nos espaços urbanos e fundadas as escolas de Serviço Social.

Um segundo momento, entre 1946 a 1980, marcado por regimes republicanos democráticos e extensa ditadura militar. Mas, ambos articulados à proposta desenvolvimentista, cujo caráter nacionalista aprofunda-se no período de autocracia burguesa (PAULO NETTO, 1991). A aceleração da urbanização, a interiorização da capital nacional com a criação do Distrito Federal, a conformação das grandes regiões metropolitanas aprofundam as contradições e o modelo desigual de crescimento do país.

No campo da assistência social, em particular em um locus de sistematização de conhecimento, a disciplina de Serviço Social - aprofundam-se as referências em métodos e técnicas relacionados ao funcionalismo e à fenomenologia. Ocorre nesse período o movimento latino-americano da reconceituação, marcado pela intenção de ruptura com o arcabouço conservador do Serviço Social. Passa-se também a dialogar com a teoria social crítica como referência de análise por uma perspectiva crítica.

Para a assistência social apenas na incorporação do viés crítico na disciplina de Serviço Social, trazido com o movimento da reconceituação nos anos 1960, é possível identificar as contradições sociais e a base das relações de classe que fundam e desenham, historicamente, a questão social capitalista. Entretanto, a dimensão espacial assume em diferentes tempos o que denominamos como uma dimensão "funcional" de operação das ações públicas de assistência, sendo relevante a esse fim, porém aparece tematizada de forma periférica em diferentes momentos históricos. Por fim, o período contemporâneo, compreende a redemocratização e, paradoxalmente, os tempos de acirramento da ofensiva neoliberal na América Latina.

Como racionalidade reordenadora dos espaços, configurando novos sentidos ao território, as políticas de recorte neoliberal passam a responder parte das demandas centrais para o procedimento de "integração" territorial, relacionado à necessidade de queda de fronteiras entre países, viabilizando o fluxo de capitais, em especial sob a sua forma finan- 
ceirizada. A crise dos Estados-nação e a universalização do capital financeiro necessitam, nessa década de 1970, de regulação específica nos campos econômico e de investimento estatal para o reordenamento social e territorial a fim de viabilizar a integração de entrada dos fluxos de capital - condição primordial de sua reprodução. Esse padrão de políticas, em sua maioria orientado pelo receituário do Fundo Monetário Internacional (FMI) e Banco Mundial (BIRD), entre outros organismos multilaterais, com base nas regras de ajuste estrutural da economia e dos Estados, considera incontestáveis a relevância do espaço e o papel do território para a reprodução do capital, gerando alterações nos perfis de políticas, que passam a ter forte caráter focalista ${ }^{21}$. Ocorre, então, o que Dagnino (2000) denomina de "confluência perversa" entre dois projetos de sociedade antagônicos, com disputas pelos sentidos da descentralização político-administrativa, da cidadania, da participação e de direitos.

Colocam-se, claramente, frente a frente, dois projetos societários: o primeiro pautado na perspectiva de universalização de direitos, de constituição de esferas públicas fortalecidas por participação societária para controle social sobre as ações estatais e, o segundo, precursor do Estado mínimo, da participação consultiva e adesista, das políticas públicas focalizadas sobre os mais pobres, da cidadania de resultados.

É nesse contexto que a aprovação da PNAS (2004) enfrenta longo percalço e, a exemplo disso, de forma concomitante os desafios de construção de um sistema territorializado de assistência social. Implementa-se e amplia-se um programa governamental de caráter distributivo, não participativo e com envolvimento paulatino de todos os municípios brasileiros, o Bolsa Família - contribuindo para o que identificamos como uma dualidade de concepções no campo da assistência social.

\section{Participação e esfera pública: possibilidades de universalização do direito no território}

Nesse último momento, apresentamos algumas reflexões a partir da breve demonstração de como a dimensão espacial "sempre" esteve presente ao se formular sobre assistência social pública, mesmo sem considerar explicitamente o território como componente estratégico da política, passando apenas na "última década a ser problematizada". Na nossa resumida incursão histórica, pudemos reconhecer a presença da dimensão espacial orientando a intervenção pública nas ações de assistência social desde os primórdios da mediação estatal junto à questão social capitalista, vinculada à constituição do urbano.

Destarte, a apropriação da dimensão espacial contribui em parte para a construção de um meca- nismo de reprodução das condições de acumulação do capital, parcialmente explicado pelas intervenções públicas que amenizam conflitos, permitindo uma "repactuação" no território e alimentando a "surpreendente persistência da coerência regional estruturada" (HARVEY, 2005). E responde, em uma dinâmica embasada em antagonismos e contradições, à exigência de criação de condições permanentes para as passagens de fluxos de capital e para o trato dos excedentes capitalistas, em uma busca incessante pela acumulação.

Nesse contexto nada simples, os desafios enfrentados pela política nacional de assistência social para afirmar-se como política pública de cidadania necessitam levar em conta que territorializar não significa, "automaticamente", universalizar, democratizar, contribuir para o enfrentamento das desigualdades e, por fim, assegurar direitos.

A relevância de consolidar processos participativos, na perspectiva do fortalecimento de esferas públicas de controle social sobre destinos, rumos e perfis da política pública, coloca-se como estratégia para a disputa do sentido de território e a ruptura com a dimensão tutelar da assistência social. De forma bastante diferente da saúde, o processo de constituição do SUAS pouco envolveu usuários/as, sendo este até hoje uma difícil lacuna a ser enfrentada.

Crescentemente, essa intervenção assume as características de construção da cidadania regulada (SANTOS, 1993), financiada pelo Estado, onde a assistência social cumpre relevante função. Nessa movimentação, diferentes instituições têm importante papel, mas o Estado é protagonista na mediação dos conflitos e da relação problemática entre condições locais e particulares e a universalidade de valores (HARVEY, 2004, p. 55).

Defendemos, portanto, que a constituição das redes socioassistenciais no território carece do debate sobre a atuação de organizações sem fins lucrativos no âmbito da política, para buscar romper com o mero papel de prestadoras de serviço. Apontamos para a necessidade de revisão do uso do fundo público, que deve ser voltado, centralmente, para o financiamento de um novo padrão de democracia.

A dimensão estratégica de apoio a entidades de defesa de direitos, as organizações da sociedade civil relacionadas a movimentos sociais urbanos, rurais, de mulheres, de afrodescendentes, de moradores de rua, de idosos, enfim, de toda a diversidade e pluralidade que hoje integra a sociedade brasileira, devem ser temas de reflexão no tratamento das condições para uma participação política efetiva e cidadã no âmbito de esferas públicas de controle social sobre o Estado brasileiro.

O fomento à interlocução entre público-alvo da assistência social e demais cidadãos/ãs e movimentos sociais atuantes por direito à cidade, à reforma 
agrária e a outras lutas, é um outro aspecto que precisa ser levado em conta, caso se queira romper com a dimensão de "insulamento" dessa política pública e com o seu "caráter residual". Essa tarefa pertence tanto ao Estado brasileiro, quanto aos movimentos sociais e entidades da sociedade civil compromissados para que princípios e diretrizes da política nacional de assistência social de fato se concretizem.

Ao identificarmos a dualidade do papel da assistência social - amenizadora de conflitos e asseguradora de direitos -, percebemos como ele financia, nos moldes de políticas focalistas distributivas, duas naturezas de organização da coerência regional estruturada, as quais contribuem claramente para a dotação de sentido dos espaços através do financiamento estatal, nos anos 1990: a) a implantação do modelo de "urbanização integrada" em áreas pobres nas metrópoles; e b) a integração pelo consumo, viabilizando melhor o escoamento de excedentes produzidos pelo capital, até os dias atuais, através da operação de programas de distribuição de renda focalizados nas populações mais pobres.

É, em período recente, no marco da IV Conferência Nacional de Assistência Social (2003), que o território é, de fato, proposto como categoria de implantação e de análise da política. Com isso, a proposição de criação do SUAS visa à integração em instâncias intramunicipais de serviços e equipamentos para a acessibilidade a esse direito. Mas, nossa investigação considera que há limites na atual proposta de territorialização tendo por norte o objetivo de constituir-se em política pública capaz de romper com a cidadania regulada, cuja identidade segundo Telles (2006, p. 90) "[...] é atribuída pelo vínculo profissional sacramentado pela lei e que o qualifica para o exercício dos direitos."

Se, de fato, não podemos afirmar que os investimentos de caráter assistencial são residuais, é preciso qualificar o que são esses investimentos hoje disponibilizados no território. E se, de fato, contribuem para o fortalecimento de seus usuários como cidadãos ativos, ou para sua inserção funcional, seja pelo consumo, seja pela capacidade de amenização dos conflitos no território, através da concessão de melhorias urbanas.

Também identificamos em nosso trabalho que, à revelia da preocupação com a construção de um método de implementação do SUAS intramunicipal, paira uma forte indefinição no âmbito da assistência social quanto a questões regionais, metropolitanas e intermunicipais. A presença da esfera estadual nessa dinâmica federativa tem propósito pouco claro, para além de sua definição normativa, sendo utilizada à mercê da composição e da cultura política de cada território. Nesse sentido, independentemente dos modelos de políticas propostos, até o atual desenho da PNAS, a pactuação federativa para a real construção das condições de descentralização é por deveras claudicante, ficando à mercê das dinâmicas políticas locais, regionais e de sua relação com o poder central, a União - constituindo-se num obstáculo imponente à sua efetiva descentralização.

A política atual expressa um modelo ainda em aberto, marcado por contradições da convivência entre antigos e novos paradigmas, tanto do campo da assistência social como da perspectiva da participação. Essas contradições expressam, em alguma medida, diferenças em torno da compreensão de território e da contribuição deste na universalização de direitos de cidadania.

Como fundamento dessas dificuldades e do mosaico de interesses que disputam o sentido da assistência social e de suas formas de territorialização, há os mecanismos de financiamento do Estado brasileiro e, no que se refere à racionalidade de financiamento da acumulação pelo Estado, consideramos em especial o "fundo público". É preciso refletir sobre seu papel, observando que há tempos, mesmo com a regulamentação dos fundos constitucionais, este tem sido permanentemente apropriado pelo capital. Por um lado, os investimentos que realiza auxiliam na criação das condições para a acumulação e, por outro, garantem parcialmente direitos - mas sua existência e aplicação têm sido, desde meados do século 20, orientados maciçamente pelo modelo de desenvolvimento em curso.

Esse aspecto deve ser levado em conta, pois tem tensionado mais para a construção de políticas de caráter distributivo e fragmentado do que assegurado intervenções participativas. Essas intervenções teriam cunho redistributivo da riqueza socialmente produzida e seriam integradoras de ações estatais junto às demais políticas públicas - que beneficiando-se dos fundos existentes no âmbito estatal, romperiam com a dicotomia entre as áreas econômica e social, integrando as políticas para além das do campo da seguridade social. 
Existem, portanto, desafios estruturais em torno da consolidação de uma metodologia que, de fato considere a dimensão territorial como uma das categoriais propositivas para formulação, análise, controle social e monitoramento da política pública de assistência social, visando romper com o que denominamos de um uso "funcional" dessa categoria. Essa metodologia deve focar-se em promover uma ruptura com antigos paradigmas da política de pensála em si e a partir de si, método que acaba perpetuando a política mais como instrumento integrante do processo de acumulação. É longo e enigmático o caminho para a afirmação de uma política pública territorializada, universalista e democrática, capaz de impulsionar a promoção da cidadania ativa na esfera local, com impacto nas dinâmicas mais estruturais.

\section{Referências}

AZEVEDO, S. Políticas públicas: discutindo modelos e alguns de implementação. In: SANTOS JUNIOR, A. O. dos et al. (Org.). Políticas públicas e gestão local: programa interdisciplinar de capacitação de conselheiros. Rio de Janeiro: FASE, 2003, p. 38-44.

BEHRING, E. Política social no capitalismo tardio. São Paulo: Cortez, 2002.

BEHRING, E. R.; BOSCHETTI, I. Política social: fundamentos e história. São Paulo: Cortez, 2007.

BRASIL. Constituição da República Federativa do Brasil. Promulgada em 5 outubro de 1988. São Paulo: Atlas, 1999.

CARVALHO, J. M. de. Cidadania no Brasil - o longo caminho. Rio de Janeiro: Civilização Brasileira, 2004.

CARVALHO, R. de; IAMAMOTO, M. V. Relações sociais e Serviço Social no Brasil - esboço de uma interpretação histórico-metodológica. São Paulo: Cortez; Lima, Peru: Celats, 1991.

CASTEL, R. Metamorfoses da questão social. Petrópolis: Vozes, 1998.

COUTINHO, C. N. Contra a corrente: ensaios sobre a democracia e socialismo. São Paulo: Cortez, 2000.

COUTO, B. R. O direito social e a assistência social na sociedade brasileira: uma equação possível? São Paulo: Cortez, 2004.

DAGNINO, E. Cultura, cidadania e democracia - a transformação dos discursos e práticas na esquerda latinoamericana. In: ALVAREZ, S.; DAGNINO, E.; ESCOBAR,A.
(Org.). Cultura e política nos movimentos sociais latinoamericanos: novas leituras. Belo Horizonte: Humanitas; UFMG, 2000, p. 61-102.

HARVEY, D. A produção capitalista do espaço. São Paulo: Annablume, 2005. (Coleção Geografia e Adjacências).

Espaços de esperança. São Paulo: Loyola, 2004.

IAMAMOTO, M. V. O Serviço Social na contemporaneidade: trabalho e formação profissional. São Paulo: Cortez, 1998.

LEAL, V. N. Coronelismo, enxada e voto. São Paulo: Alfaômega, 1976.

LOAS - Lei Orgância de Assistência Social, 1993. Coletânea de Leis e Resoluções. Rio de Janeiro: CRESS/RJ, 2000.

MYASAKA, C. R. A reforma urbana e o subúrbio carioca na sua historiografia. 2007. Disponível em: <http:// ramaldesantacruz.com/reforma1.pdf $>$. Acesso em: 20 set. 2009.

OLIVEIRA, F. Os direitos do antivalor: a economia política da hegemonia imperfeita. Petrópolis: Vozes, 1998.

O elo perdido: classe e identidade de classe na Bahia. São Paulo: Perseu Abramo, 2003. (Coleção Histórica do Povo Brasileiro).

PASTORINI, A. A categoria 'questão social' em debate. São Paulo: Cortez, 2004.

PAULO NETTO, J. Ditadura e Serviço Social. São Paulo: Cortez, 1991.

PEREIRA, T. D. Política nacional de assistência social e território: um estudo à luz de David Harvey. Tese (Doutorado) - Universidade Federal do Rio de Janeiro, 2009.

PIERSON, P. Increasing Returns, Path Dependence and Study of Politics. American Political Science Review, v. 94, n 2, p. 251-267, Jun. 2000.

PNAS - Política Nacional de Assistência Social. Versão oficial. São Paulo: Cortez, 2004.

RIBEIRO, L. C. Q.; CARDOSO, A. L. Da cidade à nação: gênese e evolução do urbanismo no Brasil. In: RIBEIRO, L. C. Q.; PECHMAN, R. (Org.). Cidade, povo e nação. Rio de Janeiro: Civilização Brasileira, 1996. v.1, 3. cap.

ROSANVALLON, P. A nova questão social - repensando o Estado providência. Brasília: Instituto Teotônio Vilela, 1998. 
SANTOS, W. G. Razões da desordem. Rio de Janeiro: Rocco, 1993.

SOARES, L. T. R. Ajuste neoliberal e desajuste na América Latina. Petrópolis: Vozes, 2001.

TELLES, V. da S. Direitos sociais: afinal do que se trata? Belo Horizonte: UFMG 2006.

\section{Notas}

1 Consideramos como definição primeira de política pública o queAzevedo (2003) denomina de qualificação mínima: "tudo aquilo que o governo decide fazer ou não fazer". É fundamental reconhecer a vastidão e a multidisciplinaridade de estudos sobre o tema. Para maiores aprofundamentos, ver: Pierson (2000) eAzevedo (2003), entre outros.

2 Partilhamos da definição de Coutinho (2000, p. 50) que considera cidadania como "[...] a capacidade conquistada por alguns indivíduos, ou (no caso de uma democracia efetiva) por todos os indivíduos, de se apropriarem dos bens socialmente criados, de atualizarem todas as potencialidades de realização humana abertas pela vida social em cada contexto, historicamente determinada."

3 Pereira (2009, p. 33) expõe que "Harvey considera ser preciso diferenciar dois momentos na obra de Marx, nos quais o espaço adquire importância. O primeiro, refere-se aos contextos socio-históricos dos lugares, aldeias e países, onde as condições materiais daquele momento histórico de produção e de reprodução do capital (a exemplo do caso da Inglaterra), determinavam qualitativamente sua forma de organização, os processos de trabalho, as condições de valorização do trabalho social e, enfim, as relações sociais historicizadas nos territórios. O segundo, vincula-se aos lugares de produção e de expressão da mais valia, às dimensões da produção, da circulação - do mercado como espaço de concretização, iniciada na produção, da transformação do dinheiro em capital, do que o autor denomina do movimento incansável do capital, o incessante movimento do ganho."

4 Questão social entendida como “ $O$ conjunto das expressões das desigualdades da sociedade capitalista madura, que tem uma raiz comum: a produção social é cada vez mais coletiva, o trabalho torna-se mais amplamente social, enquanto a apropriação de seus frutos mantém-se privada, monopolizada por uma parte da sociedade" (Iamamoto, 1998, p. 27). Na mesma linha, Pastorini (2004) ressalta a importância de reconhecer que as expressões da questão social não são idênticas em todas as formações sociais capitalistas, nem, tampouco, únicas nos diferentes momentos históricos e conjunturais, considerando que esta tem sua origem com a emergência do capitalismo e não consegue superar suas questões estruturais, ainda que as mudanças no mundo da produção impinjam novas nuances a suas manifestações. Partilhamos do consenso existente (Behring; Boschetti, 2007), no campo do debate teórico da disciplina de Serviço Social, que não existe uma "nova" questão social, em divergência com autores como Rosanvallon (1998) e Castels (1998).

5 A configuração do SUAS decorre de mais de duas décadas de truncado processo de construção dessa política no Brasil, visando alçá-la ao status de política pública integrante do campo da Seguridade Social e orientada pelos princípios constitucionais (BRASIL, 1988) e pelaLOAS (1993).

6 É preciso ponderar que a atual PNAS traz na nascente histórica contradições ao inspirar-se no modelo de universalização do SUS, sem sequer conseguir integrar-se com essa política do campo da Seguridade Social.

7 O conceito de "coerência regional estruturada" é chave na teoria de Harvey e "as formas e as tecnologias de produção (padrão de utilização de recursos pelas conexões interindústrias, formas de organização, tamanho de empresas), as quantidades e qualidades de consumo (o padrão e estilo de vida tanto dos trabalhadores como da burguesia), os padrões de demanda e oferta de mão de obra (hierarquias das habilidades de mão de obra e processos sociais de reprodução, para assegurar a oferta dos mesmos) e as infraestruturas físicas e sociais" (HARVEY,2005,p. 146).

8 A construção dessa categoria por Harvey (2005) contribui para a desmistificação do espaço como algo natural, trabalhando-o sempre como espaço social. Assinalamos que, especificamente, a partir da dinâmica de acumulação capitalista, o espaço como espaço social, passa a ser dotado de sentido, compreendendo as contradições e as disputas impressas pela racionalidade da acumulação e das possibilidades do capital em enfrentar temporal e territorialmente as contradições que gera no próprio processo de busca da superacumulação. No que tange a uma forma de expressão espacial da projeção do capital e sua relação com o tempo, a circulação do capital precisa ser concluída no tempo de rotação socialmente necessário(HARVEY, 2005,p. 136), isto é, no tempo médio necessário para girar certa quantidade de capital em relação à taxa média de lucro sob condições normais de produção e de circulação.

9 Em Pereira (2009, p. 37 )encontramos a afirmação de que "Harvey (2005) chama a atenção para uma contradiçãocentral, relacionada ao fato que, mesmo como um obstáculo a ser superado, a dimensão espacial precisa ser apropriada pelo capital com vistas à sua organização e à garantia da circulação da mercadoria no tempo socialmente necessário para sua realização - justamente como forma de superar o espaço pelo tempo."

10 A relevância estratégica do fundo público para garantir as condições de acumulação é apresentada em clássico texto 
de Oliveira (1998) e problematizada com divergências quanto à caracterização de antivalor por Behring (2002).

11 Para Leal, em sua obra clássica de 1949 sobre coronelismo, este se constitui em uma manifestação do poder privado, a qual coexiste com regime político de extensa base representativa e possui na estrutura agrária, em especial no latifúndio, a sustentação de seu poder. O coronelismo também denota de trocas de favores do poder público em ascensão à época, com os chefes locais. Para maior aprofundamento, pesquisaremLeal (1976)e Carvalho(2004).

12 Segundo Carvalho (2004), a noção de cidadania republicana erabastante formal.Amaioria da população era de fato excluída dos processos eleitorais, embora ocorressem eleições ao longo de todo o período de 1822 a 1930. Negros, mulheres, analfabetos (a maioria da população) e pessoas que possuíssem renda abaixo de 100 mil réis não tinham direito ao voto. Quando a escravidãoé abolida, jáé bastante pequeno o contingente de escravos, mas a população afrodescendente não tem direitos civis, políticos e sociais reconhecidos ou muito menos equiparados à população branca.

13 Agrande reformaurbanainiciada em 1902 por Pereira Passos e com direta inspiração em Haussman, é fortemente relacionada às condições necessárias para a passagem do escravismo para o capitalismo, com clara centralidade do Estado em sua promoção (MYASAKA, 2007). Na segunda metade do século 19, o Rio de Janeiro sofre com o crescimento populacional, a crise habitacional, o aumento da circulação de mercadorias, os surtos epidêmicos, as ruas estreitas e congestionadas. Essa conformação urbana não atendia mais, no início do século 20, aos interesses dos capitalistas estrangeiros e brasileiros, nem tampouco aos do Estado republicano. Tais elementos incrementam a chamada questão social do período.

14 Da mesma forma que a dimensão territorial apresenta tematização recente na trajetória da assistência social, a emergência do urbano como temática também é algo novo mesmo nos países europeus - não fugindo à regra nos latinoamericanos, em especial no Brasil. Não obstante, essa percepção do urbano como uma dimensão com problemas próprios, e consequente necessidade de políticas e intervenções públicas, ocorre de forma diversa na Europa, naAmérica Latinae, particularmente, no Brasil.

15 Carvalho (2004) lembra-nos que a independência da colônia em relaçãoa Portugal (1822) não introduziu grandes mudanças no panorama dos direitos e da cultura escravista, nem foi pautada por processos internos de revoltas, sendo bastante pacífica e pactuada entre as elites brasileiras, da Coroa e da Inglaterra. Já a primeira Constituição Federal (1824) trouxe modificações no que se refere ao reconhecimento dos direitos e, considerando sua forte característica liberal, regulou os direitos políticos, estabelecendo quem podia equem nãopodia votar. No entanto, a mesma ignora a escravidão e estabelece os três poderes, oExecutivo, Legislativo e o Judiciário, criando ainda o poder Moderador, exclusivo do Imperador.

16 No caso em estudo de Oliveira, a cidade de Salvador, capital do estado da Bahia. A exemplo da emergência do capital bancário, ele cita o Banco da Bahia, protoforma do Banco do Brasil e da criação da Companhia de Seguros da Bahia. No Rio de Janeiro, as caixas de pensão são um exemplo similar.

17 Pereira afirma que "[...] o início de uma sistematização do conhecimento produzido a partir da intervenção profissional e, especificamente, as iniciativas de uma reflexão sobre o Serviço Social e sua relação com políticas sociais ocorrem timidamente partindo da academia apenas nos anos 1950, tendo na América Latina lugar de expressão no Congresso Latino-Americano de Trabalhadores Sociais (Celats). Ou seja, apenas um pouco antes dos anos 1960, abre-se o debate para além do foco no indivíduo e inicia-se de fato reflexão em torno das políticas sociais, exposta em congressos da profissão. Estas são centralmente tematizadas a partir da década de 1960 nas faculdades brasileiras de Serviço Social, em especial as públicas, federais e estaduais" (PEREIRA, 2009,p.100).

18 Ainda que o foco de nossa reflexão não esteja centrado no sujeito profissional, mas nas expressões da manifestação da dimensão territorial em diferentes tempos históricos, há de se considerar a relevância da profissão e de seus sujeitos profissionais tanto para a sistematização de conhecimento quanto para influências nos rumos da política pública em diferentes tempos históricos. Se a profissão tem início fortemente inspirada nos preceitos religiosos do humanismo cristão, é a partir dos anos 1950, período em que se amplifica o discurso e a ideologia desenvolvimentistas no Brasil, que a profissão referencia-se no viés teórico positivista do funcionalismo, a pretexto de maior qualificação técnica de sua intervenção social, procurando conferir à profissão maior estatuto dentro da divisão social do trabalho. $\mathrm{Na}$ operacionalização das políticas públicas existentes entre os anos 1930 e 1960, no âmbito da abordagem teóricometodológica da disciplina de Serviço Social, respaldada majoritariamente no funcionalismo, as opções metodológicas dividiam a intervenção em Serviço Social de "caso" (com a perspectiva de ação sobre o indivíduo), de "grupo" e de "comunidade" e expressavam, ainda que distante de alguma elaboração sobre a relevância do lugar, o reconhecimento, mesmo que funcional, da inserção socioespacial do sujeito.

19 Soares ressalta que "[...] no que diz respeito à tão propalada estratégia de descentralização utilizada pelas políticas neoliberais, ela não tem como propósito democratizar a ação pública e sim viabilizar a privatização, deixando para o nível local a responsabilidade do financiamento, da administração e da produção de serviços" (SOARES, 2001, p. 47).

20 Para maior aprofundamento sobre os impactos do Ajuste Fiscal, promovido a partir do Consenso de Washington sobre 
o padrão de políticas públicas e de investimentos pautados pela lógica do ajuste fiscal, ver Soares (2001).

21 Para Pastorini (2002) “[...] o projeto liberal na busca de gerar superavit primário para pagamento dos credores, aplica uma drástica política de redução do gasto público, especialmente aquela destinada a financiar políticas sociais". Assim, a autora demonstra como, a partir dos ajustes econômicos, realizados pelos governos desde a década de 1990, o Brasil passa a pagar um alto preço pela sua integração na economia globalizada - preço este mensurado a partir dos organismos multilaterais, reguladores das dinâmicas econômicas mundiais.

\section{Tatiana Dahmer Pereira}

tatianadahmer@ig.com.br

Doutorado em Planejamento Urbano e Regional pelo Instituto de Pesquisa e Planejamento Urbano e Regional da Universidade Federal do Rio de Janeiro (IPPUR/UFRJ)

Professora Adjunta da Escola de Serviço Social da Universidade Federal Fluminense (UFF)

\section{UFF - Escola de Serviço Social}

Campus do Gragoatá - Bloco E

São Domingos

Niterói - Rio de Janeiro

CEP: 24210-201 